\title{
Gender and Corruption in Business
}

\author{
MICHAEL BREEN*, ROBERT GILLANDERS**, GEMMA MCNULTY ${ }^{\dagger}$ \\ \& AKISATO SUZUKI ${ }^{\ddagger}, 8$
}

*School of Law and Government, Dublin City University, Dublin, Ireland, **Department of Economics, Hanken School of Economics, Helsinki, Finland, ${ }^{\dagger}$ Visiting Fellow at the Latin American and Caribbean Studies (LACS) Program, Northwestern University, Evanston, IL, USA, ${ }^{\dagger}$ Department of Political and Social Sciences, European University Institute, San Domenico di Fiesole, Florence, Italy, ${ }^{\S}$ Institute for International Conflict Resolution and Reconstruction, Dublin City University, Dublin, Ireland

\section{Online Appendix}

Summary statistics: extended discussion

Table 1 in the main text displays the summary statistics of our main variables. Here we discuss the characteristics of Obstacle, Female Owners, and Female Top Managers. Our second dependent variable, Obstacle, has a mean of 0.40 . Since it is a dummy variable, this means that 40 per cent of the companies which answered the corresponding survey question $(N=53,532)$ stated that corruption is a major or very severe obstacle to their operation. This is an important finding by itself, suggesting that many companies surveyed were struggling with corruption.

Our main explanatory variables, Female Owners and Female Top Managers, are also dummy variables and have means of 0.36 and 0.17 respectively. Therefore, 36 per cent and 17 per cent of the companies which answered the corresponding questions have female owners and female top managers respectively. These figures suggest that firms are more likely to have a woman as an owner than as a top manager. One caveat is that the number of the available observations (that is, the number of the companies which answered the corresponding questions) is significantly smaller in Female Top Managers than in Female Owners (30,705 versus 49,239). However, it is not obvious that a higher number of missing values in Female Top Managers would be correlated with a lower rate of companies which have female top managers (that is, whether those companies which did not answer the question would have a higher rate of female top managers than those which answered it).

\section{Cultural and institutional context}

Tables A1 and A2 present estimates where our sample is divided by three variables: regime type, rule of law, and culture. These tests are motivated by the argument that particular institutional and cultural factors may activate the relationship between gender and corruption, so that we may need different theoretical explanations for different sub-samples. ${ }^{1}$ For example, committing bribery in a democratic regime or under a strong rule of law might be more risky because detection and punishment is more likely. If risk aversion matters, then women may be less inclined to engage in bribery under these types of regimes. However, refusing to engage in corrupt activities might be an even riskier strategy in some situations, particularly if the refusal is seen to challenge a regime that supports or tolerates widespread corruption. Religious and cultural traditions may also be consequential, as some traditions stipulate how men and women ought to behave in a business context, and define how society should deal with transgressors. 


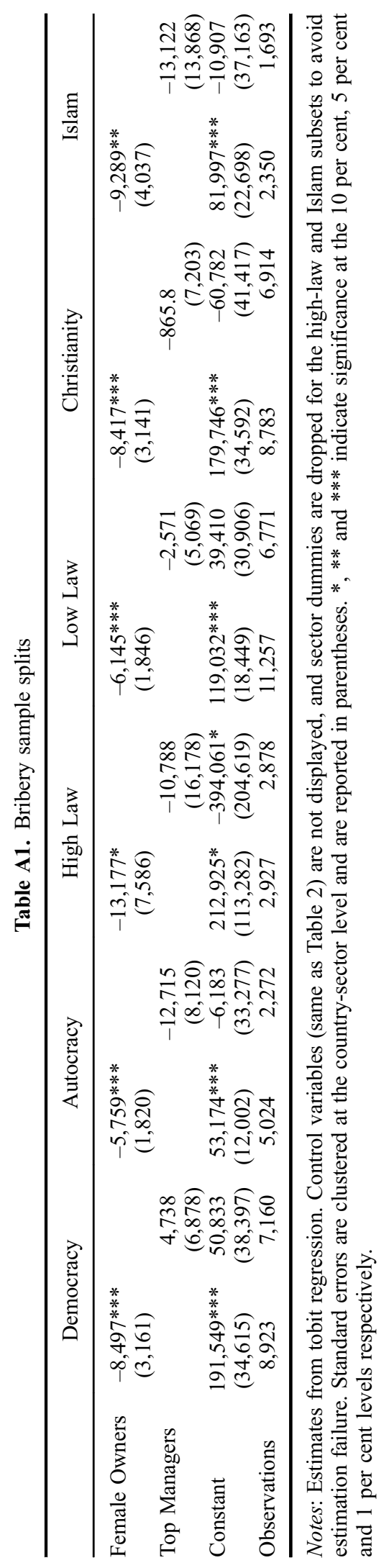




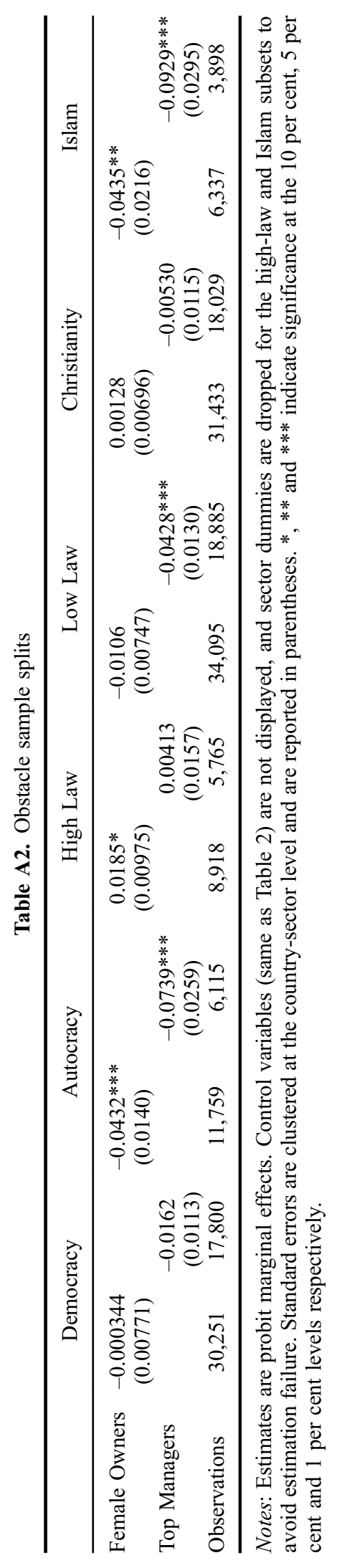




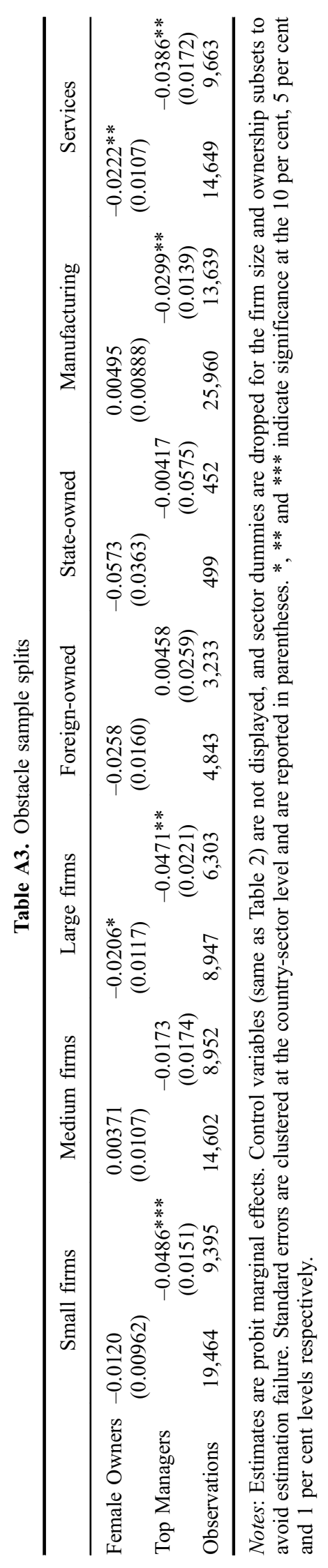


To operationalise regime type (democracy versus autocracy) we use the aforementioned Polity2 scale (http://www.systemicpeace.org/polity/polity4.htm). Following the literature in political science, we code a country as a democracy if its Polity2 score is greater than or equal to six, and otherwise as an autocracy. We also use the aforementioned Rule of Law variable by the World Governance Indicators (Kaufmann, Kraay, \& Mastruzzi, 2011). If a country's Rule of Law score (ranging from -2.5 to 2.5) is equal to or higher than 0, it is coded as a high rule-of-law country, and otherwise as a low rule-of-law country. Like regime type, a low rule of law environment may activate the relationship between corruption and gender, as the ease of using corruption, as well as the detection and punishment of corrupt activities may differ considerably. Our proxy for cultural contexts is religion, which we obtain from the Correlates of War World Religion dataset (Maoz and Henderson, 2013). We present estimates for Christian-majority and Islam-majority countries. A religion is coded as a majority if at least half of the total population is a believer. ${ }^{2}$

Tables A1 and A2 report estimates separately for female owners and female managers as including both dramatically reduces the number of observations in many sub-samples. Starting with Table A1, we find that female ownership is statistically significant and associated with smaller bribes in all of our samples. Gender seems to matter more in countries where the risk of detection and punishment is greater, as indicated by the size of the coefficients of female owners in the subsets of democratic and high rule-of-law countries, compared to those in the subsets of autocratic and low rule-of-law ones. That said, the Enterprise Surveys do not contain a direct measure of risk toleration so our findings must be interpreted with caution. Overall, the association between women and bribery seems to vary substantially across different political and institutional contexts but not across the religious traditions that we have tested.

Turning to our second dependent variable, the evidence suggests that women in positions of influence tend to create a view that corruption is less of an obstacle to doing business, but only in certain contexts. In Table A2, female ownership and management is associated with a statistically significant reduction in Obstacles under autocracy, and in primarily Islamic countries. Furthermore, female top managers are statistically significant in the low rule-of-law sample. Conversely, in the high rule of law sample female ownership predicts a higher likelihood of thinking corruption is an obstacle. These findings suggest that the relationship between gender and corruption perceptions varies across cultural and institutional contexts; specifically in places where the rule of law is weaker, in primarily Islamic countries, and under autocratic regimes.

\section{Obstacles: firm size and sector}

Table A3 presents our findings from sub-samples of Obstacles defined by firm size and economic sector. Estimates are reported separately for female owners and managers in order to maximise sample size. In these models, a female top manager is more likely to be associated with a change in corruption perceptions. This is true in relation to small firms and large firms but not medium-sized firms, as well as manufacturing and services. Like our estimates for bribery, there is no association between gender and corruption in either foreign or state-owned firms.

\section{Notes}

1. For a discussion of how gender and corruption may vary under different institutional arrangements see Esarey and Chirillo (2013).

2. In most countries majority religions do not change during the period of the survey except for Cameroon, Nigeria, Eritrea, and Vietnam, where the majority religious group sometimes failed to pass the threshold of half a population. For Cameroon, Eritrea, and Vietnam, the Enterprise Survey data were collected in 2008, so the 2010 observations of the religion data were used; in Nigeria, the company data were 2006, so the 2005 observation of the religion data were used. 


\section{References}

Esarey, J., \& Chirillo, G. (2013). "Fairer Sex" or purity myth? corruption, gender, and institutional context. Politics \& Gender, 9, 361-389. doi:10.1017/S1743923X13000378

Kaufmann, D., Kraay, A., \& Mastruzzi, M. (2011). The worldwide governance indicators: Methodology and analytical issues. Hague Journal on the Rule of Law, 3, 220-246. doi:10.1017/S1876404511200046

Maoz, Z., \& Henderson, E. A. (2013). The world religion dataset, 1945-2010: Logic, estimates, and trends. International Interactions, 39, 265-291. doi: 10.1080/03050629.2013.782306 